\title{
"The Propellers of My Life" The Impact of Domestic Violence Transitional Housing on Parents and Children
}

\author{
Leila Wood $^{1}$ (D) Maggy McGiffert ${ }^{1} \cdot$ Rachel A. Fusco $^{2} \cdot$ Shanti Kulkarni $^{3}$
}

Accepted: 29 December 2021

(c) The Author(s), under exclusive licence to Springer Science+Business Media, LLC, part of Springer Nature 2022

\begin{abstract}
Housing and homelessness are frequent issues facing domestic violence (DV) survivors and their children. Several DV programs provide transitional housing (DVTH) to address the housing needs of DV survivors and their children. Despite wide use, little is known about the impact of DVTH, especially on child and parenting related needs and outcomes. Multiple structured interviews (82) were conducted with 27 parents with minor children living in DVTH in order to explore housing program experiences. Thematic analysis techniques produced three themes and seven subthemes about DVTH impact on parenting and child wellness. Overarching themes include: (1) DVTH helps to strengthen the parent-child relationship through a focus on family connection and health; (2). Transitional housing provides an opportunity for family stability via housing, material, and economic stability; (3). Time at DVTH allows family to access a diverse range of trauma-informed resources and social support to meet family goals. Barriers to these potential impacts are explored. Implications for practice with youth and parents include the need for extensive mental health and legal advocacy, programmatic models that emphasize resources, safety and the transition to permanent housing, and build on family strengths. Further research is needed to evaluate DVTH program outcomes.
\end{abstract}

Keywords Housing $\cdot$ Trauma-informed care $\cdot$ Domestic violence $\cdot$ Poverty $\cdot$ Children exposed to domestic violence . Parenting

Housing and homelessness are frequent issues facing domestic violence (DV) survivors and their children. One in five homeless women report DV as the primary cause of homelessness (Jasinski et al., 2002) and housing is the

Leila Wood

leiwood@utmb.edu

Maggy McGiffert

mmmcgiff@utmb.edu

Rachel A. Fusco

Rachel.Fusco@uga.edu

Shanti Kulkarni

Skulkar4@uncc.edu

1 Center for Violence Prevention, Department of Obstetrics and Gynecology, The University of Texas Medical Branch, 301 University Blvd, Galveston, TX 77555-0587, USA

2 Georgia Athletic Association Professor in Health and Well-Being, School of Social Work, University of Georgia, Athens, USA

3 Department of Social Work, College of Health and Human Services, UNC Charlotte, Charlotte, USA most requested service, and most frequently unmet need, of DV survivors (Wood et al., 2019; National Network to End Domestic Violence, 2021). To address the housing needs of DV survivors and their children, DV programs frequently provide transitional, or supportive housing. Domestic violence transitional housing (DVTH) typically lasts 12-24 months, and is a housing model bolstered by supportive services to address safety, wellness, and economic needs with the goal of accessing safe and affordable permanent housing (Clark et al., 2019; Klein et al., 2019). Despite wide use, little is known about the impact of DVTH (Klein et al, 2019; Rizo et al., 2020), especially on child and parenting related needs and outcomes.

Previous research has documented the deleterious impact of DV on children's health and survivor parenting (Felitti, et al, 1998; Gurtovenko \& Katz, 2020) as well as the strong role of housing as protective for positive child welfare outcomes (Fowler et al, 2017). However, the short-and longterm impact on the lives of survivors and their children of housing provided by DV programs- which serves over 10,000 children any given day (National Network to End 
Domestic Violence, 2021)- is understudied. Additionally, as more DV programs face funding reductions for DVTH and other housing programs (NNEDV, 2021), outcome data becomes increasingly crucial for evidence-based programming planning. The need to understand the potential impact of DVTH, with its supportive model and attention to trauma impacts, is crucial to expanding community-based interventions to address intergenerational experiences of violence. Given the lack of research on children and family outcomes, including parenting experiences in DVTH, further study is needed to assess program impact. Qualitative methods in the form of repeated structured interviews from 27 parents in one DVTH program were used to explore the research question: What are DV survivors' perceptions about the impact of domestic violence transitional housing (DVTH) on their parenting and child wellness?

\section{Literature Review}

\section{The Impact of Domestic Violence on Children and Families}

Domestic violence (DV) interferes with immediate and longer-term safety and stability for survivors and their children. Children may witness the physical, emotional, or sexual abuse of their primary caregivers, and may fear for the safety of their siblings or themselves (Humphreys et al, 2019). Indeed, nearly $18 \%$ of youth in the United States have been exposed to parent/guardian physical DV in their lifetime (Hamby et al., 2010). Studies of DV exposure on children have detailed its negative impact on mental health (Hamby et al., 2011), cognitive development (Enlow et al., 2012), and physical health (Bair-Merritt et al., 2006). The effects of DV exposure are evident in children as young as infancy (Udo et al., 2016), and can persist into adulthood (Mbilinyi, 2015). Witnessing DV during childhood increases risk for many negative outcomes in health and well-being in later life, as illustrated bv Felitti et al., seminal (1998) study on adverse childhood experiences (ACEs). Exposure to DV in childhood has been associated with later child maltreatment perpetration (Anderson et al., 2018; Herrenkohl et al., 2008), substance misuse, and dating violence victimization and perpetration (Karlsson et al., 2016; Temple et al., 2013). Thus, DV exposure during childhood can set in motion trajectories of risk that extend into later life.

Children exposed to DV are not only impacted by the violence that they witness, but can also be negatively impacted when violence interferes with children's ability to access the support and stability they need in order to heal from any trauma they experience. Survivors living in abusive relationships are often hindered in their ability to effectively parent their children (Gurtovenko \& Katz, 2020). Abusers may undermine survivors' parental authority as part of the relationship dynamics (Bancroft et al., 2012). Adult DV survivors who suffer from negative physical and mental health outcomes, as well as reduced economic and housing stability, may have less personal and social resources to be an effective parent (Black et al., 2011; Breiding et al., 2017; Clough et al., 2014). Children and parents experience disrupted relationships which otherwise could function as an important protective factor for DV exposed youth (BairMerritt et al., 2006; Carpenter \& Stacks, 2009).

One particularly destabilizing impact of DV for parents and children is housing instability and homelessness (Bai et al, 2019; Bassuk et al, 2014), which further reduces safety and destabilizing families independent of DV. Many DV survivors facing housing insecurity have minor children, increasing family vulnerability when trying to leave a violent relationship. Homelessness is detrimental for children and families, leading to increased stress, hunger, mental and physical health challenges, interference with abilities to selfregulate and concentrate in school, and increased chance for removal of children by child welfare systems (Annor \& Oudshoorn, 2019; Bassuk et al., 2020; Shinn et al., 2017). Additionally, racial disparities among families who experience both DV and homelessness and housing insecurity exist, especially for Black families who face homelessness at the most disproportional rates, which lead to increased experiences of structural racism, in systems like child welfare, and community violence (Olivet et al, 2021; Rochelle, 2017; Shinn et al., 2017). Despite extensive evidence of the negative impact of DV on parenting, there is little guidance about the role of community-based interventions, like housing, on the reduction of family risk factors, such as decreased safety and isolation or on the enhancement of family protective factors, such as social support and resource.

\section{Parenting and Domestic Violence}

Domestic violence can lead to decreased positive parenting behaviors and increased child abuse and neglect (Chiesa et al, 2018; Postmus et al, 2012). A positive attachment relationship between a survivor and child can offset the negative impact of DV. Attachment theory focuses on the importance of a strong and healthy bond with a caregiver as an essential part of children's positive health and development (Bowlby, 1973). Insecure attachment in children has been linked to such negative outcomes as externalizing problems (Fearon et al., 2010), adverse health conditions (McWilliams \& Bailey, 2010), and depression (Jinyao et al., 2012), while secure attachments have been shown to ameliorate risks and contribute to positive outcomes (Cyr et al., 2014). The context of child-parent relationships is acknowledged to strongly influence the attachment bond in important ways (Zeanah and, 2018). Studies have examined the challenges mothers 
who are DV survivors often face in developing healthy attachments with their children (e.g., Levendosky et al., 2011), although some studies have shown that strong maternal bonds can reduce the negative impact of child exposure to violence (Houston \& Grych, 2016). Research has shown that the negative impact of DV exposure can be mitigated by secure maternal attachment and emotional support (Fusco, 2017). Given the deeply interconnected experiences of DV survivors and their children, programs and policies that support healthy parent-child relationships and healing following DV are critical. Housing may be a particularly impactful intervention that can provide opportunities to improve outcomes for children exposed to DV.

\section{Transitional Housing, Domestic Violence, and Children}

DV programs across the country have responded to the long-term housing barriers faced by DV survivors with a number of programming solutions, rapid re-housing vouchers, and transitional or supportive housing. While over $75 \%$ of domestic violence programs offer emergency shelter, transitional housing (DVTH) is offered in only $44 \%$ of DV programs in the United States (NNEDV, 2021). DVTH typically refers to HUD- or Office on Violence Against Women-funded housing offering up to two years (or longer with HUD approval) of stable housing, with a supportive advocacy service framework and with the goal of moving individuals and families towards independent living (Clark et al., 2019; CFR §, 2020). Programs often operate on a "housing first" philosophy that people need safe housing before they can address other challenges, such as mental health needs or employment (Bai et al., 2019; Nnawulezi et al., 2018). Program goals are typically to improve survivor safety, increase self-sufficiency via resources and connection, improve physical and mental health, and secure permanent housing (Sullivan, 2018). Housing units are either clustered, with separate apartments typically owned or rented by the DV program and sometimes co-located with the shelter and other programs or scattered, located around the community. At the end of the term, DV survivors must move. This housing model frequently involves comprehensive voluntary services for DV survivors and their children, including counseling, employment and education assistance, legal services, parenting classes, substance abuse support, and permanent housing assistance (Authors, 2019b; Baker et al., 2009).

Despite the widespread use of DVTH, programmatic impact, reach, and sustainability remain largely untested (Clark et al., 2019; Klein et al., 2019). Evaluations have shown mixed experiences for DV survivors living in transitional housing, with some women experiencing sleep disruption and emotional distress in these environments
(Humphreys \& Lee, 2005; Mountain, 2015) and others demonstrating improved mental health outcomes post DVTH (Mekolichick et al., 2008). Some available evidence indicates DVTH programs may lead to reduced violence exposure and increased economic stability (Clark et al., 2019; Klein et al., 2019; Rizo et al., 2020). Research from child welfare indicates housing stress is associated with increased child maltreatment, CPS involvement, and maltreatment death (Chandler et al., 2020), yet housing programs significantly reduce abuse/neglect and enhance family stability (Fowler et al., 2018; Mbilinyi, 2015).

While previous studies have demonstrated the connection between safe housing and the reduction of child abuse and neglect and DV (Fowler et al., 2017, 2018; Mbilinyi, 2015), previous work has failed to examine the role of the DVTH setting on parenting and child wellness. As more DV programs face funding cuts for housing programs (NNEDV, 2021), and the documentation of the need for services for children exposed to DV grows (Wood et al., 2021; Chanmugam and Hall, 2012; Etherington \& Baker, 2018), research is urgently needed to examine the role of community level programs in the safety and stability of families who have experienced DV. Given the nascent state of the research, qualitative methods are best poised to begin exploration of DVTH program impact on survivor parents and their children. This study used repeated, structured interviews from a large site-based DVTH in the Southwest to explore survivor parent experiences and perception of potential program benefits related to parenting and child wellness.

\section{Methods}

Data for the current study came from a broader process evaluation of a 50-unit project-based DVTH site in a Southwestern city conducted by an external study team. The DVTH site was part of a larger DV focused agency serving survivors in a large urban county. The vast majority of DVTH residents at the program lived in the agency's emergency shelter before staying in DVTH. The DVTH program is over 20 years old and serves low-income and homeless adults and families who have experienced interpersonal violence. The program provides apartments, primarily clustered units, with a few scattered units, and supportive services, including advocacy. These services are voluntary and specialized to address issues resulting from violence, like trauma, safety, economic barriers, and basic needs. Participation in the DVTH program lasts 12 months with the option to extend up to 24 months, based on the individual needs of the resident. 


\section{Procedures}

DVTH program residents were invited to participate in an evaluation to understand their experiences in the DVTH program and assess potential impacts. Participants were considered eligible for the evaluation if they were over 18 years old, the heads of households at the DVTH program, and had entered the program in the 6-months prior to the onset of the study or began living at DVTH during the 18-month recruitment period. Residents who were willing to participate completed an initial interview and a followup interview approximately every three months for the time that they remained in DVTH. Participation in the evaluation was voluntary. Resident participants were initially recruited through promotional print and electronic fliers with information about the study. Program staff also shared information about the study with residents and the study team members conducted onsite study promotion. Interviews with DVTH residents were conducted in both English and Spanish. Residents who participated received $\$ 25$ for each interview. The study was reviewed by the first author's former institutional IRB and was determined to preclude IRB oversight as the study was determined to be a quality assurance project and not human subjects' research. The evaluation team adhered to best practices for safety and confidentiality in DV and sexual assault research (Sullivan \& Cain, 2004) and followed informed consent guidelines. Strategies used included ongoing assessment of safer contact methods, trauma-informed interview approaches, and access to resource referrals as requested.

\section{Protocol}

Residents were interviewed using a structured, mixed methods interview protocol. Interviews took 45-75 min and were conducted by members of the research team with experience working with DV survivors. The interview protocol focused on several dimensions including safety and abuse experiences; housing and economic stability; well-being, including mental health, social support, hope; family needs and goals; child(ren) needs, experiences and strengths. Open-ended questions included "Could you just tell me, in your own words, what [DVTH program] staff have done for and with you, if anything, to help you address any of these issues?; "What are your main goals right now for you (and your kids)?"; and "What are your main concerns and worries for yourself (and your kids), if any?" Data for this study comes from the qualitative portion of the structured interview.

\section{Participants}

Over the span of 18 months, $30 \mathrm{DV}$ survivors living in DVTH were enrolled in the study and participated in an initial interview. Participants were then eligible for an interview approximately every 3 months, for up to 4 potential interviews total. Twenty-six participants completed a 2nd interview; 16 completed a 3rd interview, and four completed a 4th interview. Repeated interviews and ongoing contact check-ins gave an opportunity to build trust and rapport and understand how needs in DVTH change over time. Of the 30 DVTH residents enrolled, 27 participants had children under 18 years old. The current study, with a focus on children and parenting, was conducted with data from these 27 participants. The 27 study participants had an average of 2.3 children per adult DVTH resident, and a range of 1-5 children living with them at least $50 \%$ of the time. The average age of the oldest child was 11.3, with a range of 1-17; and the average age of the youngest child was 6.3 with a range of $0-17$. All residents were female-identified. See table one for participant demographic information (Table 1).

\section{Data analysis}

To enhance our understanding of the impact of DVTH on parenting and the parent-child relationship, the study team used thematic analysis methods of repeated structured interviews with open ended questions with 27 DVTH residents over a total of 82 interviews. Thematic analysis is an analytical strategy used to find patterned meaning, or themes, within a phenomenon and ideal for discovery within a new or established event (Braun \& Clarke, 2006, 2021). Transcripts were created by a professional transcription company from audio recordings and then reviewed and de-identified by two study team staff members. For the larger evaluation, repeated interviews were first reviewed for familiarization by three study members

Table 1 Participant demographic information

\begin{tabular}{ll}
\hline Age & T1 (27) \\
\hline $25-34$ & $41 \%(11)$ \\
$34-44$ & $37 \%(10)$ \\
$45+$ & $22 \%(6)$ \\
Primary language & \\
Spanish & $33 \% \%(9)$ \\
English & $67 \%(18)$ \\
Race/Ethnicity & \\
Black & $22 \%(6)$ \\
Latinx & $48 \%(13)$ \\
Other & $30 \%(8)$ \\
Education & \\
Middle School/Some High School & $52 \%(14)$ \\
High school/GED & $26(7)$ \\
Any college & $22(6)$ \\
Currently in school & $26 \%(7)$ \\
\hline
\end{tabular}


and a preliminary codebook was created with codes related to children, parenting, health and mental health, service access, experience and needs. The rest of the transcripts were then analyzed line-by-line and coded by two team members, with the third member's input in team meeting. This team refined the codebook during analysis as new insights were developed. The team met regularly to discuss themes as they developed, and discuss their own impressions and positionality as researchers and former practitioners. For this study focused on children and parenting, codes from original analysis related to DVTH, parenting, programmatic and children's experiences were analyzed to answer the research question. All four authors reviewed data for familiarization, themes were developed by the first and second author, and refined by the third and fourth author related to the research question. Data were analyzed and themes developed both across case (participants) and over time (by time point) for themes about program impact related to children and parenting. The concept of information power (Malterud et al., 2016) rather than saturation, guided this study. High levels of information power were present in the current study, include a dense sample belonging to the target study group; strong dialogue quality; and an established theoretical background of DV services. Quality indicators aligned with thematic analysis were used (Braun \& Clarke, 2021) including an audit trail of analysis in Atlas.ti; frequent reflexive memos documenting positionality and reaction to data; and the use of co-researchers in theme development. Critically, group coding and theme development was used to name and define clear themes related to the research question (Braun \& Clarke, 2021).

\section{Results}

Three themes and seven subthemes related to the perceived impact of DV-specific transitional housing on parenting and child wellness are presented below. Summary themes on the impact of DVTH on parenting and child wellness indicate that: (1). DVTH helps to strengthen the parent-child relationship through a focus on family connection and health, though co-parenting can challenge the bonding opportunity; (2). Transitional housing provides an opportunity for family stability via housing, material, and economic stability, but feelings of safety can be compromised by community and environmental issues; (3). Time in DVTH allows families to access a diverse range of trauma-informed resources and social support to meet family goals, which, while overwhelmingly described as helpful, can be diminished by inconsistent service quality and availability. Themes are detailed below.

\section{Strengthening the Parent-Child Relationship}

Participants perceived that one impact of DVTH was a strengthened parent and child connection. Families had greater ability to focus on each other, and mental health supports enhanced parent-child relationships. However, these impacts were dampened by co-parenting challenges and safety concerns.

\section{Time to Focus on Each Other}

Transitional housing is often the first time parents and children are living alone without the abusive partner and outside of the supervisory context of shelter. This provides both opportunities and challenges for the parent-child relationship. In many cases, despite environmental challenges, participants expressed that DVTH allowed a safe and stable climate for parents and children to repair and enhance their relationships after violence and trauma. One impact of DVTH was that parental and child relationships improved, as did child behavior, throughout the program duration for many participants in this study. One DVTH resident noted "Ever since I've been here, the kids have been a little bit more peaceful. It's just they fight a lot because that's all they seen half of their life." (P16). Another participant talked about the changes since moving in her school-aged son.

Before [son's name] used to be keeping everything in and then kick something or get mad or call somebody, "You're stupid", you know what I'm saying? but now he is very, "I don't like that or this happened to me." He is very verbal now. It's all right kid. He said "shit", but hey, he said it. (P4)

Changes in her child's behavior were viewed by this participant and others as a benefit of the program and a sign of healing. During their time at DVTH, parents were able to focus on different ways to communicate as family, especially after initial safety was established and resource needs were met after move in. Able to parent in their own way without control or coercion, several residents were able to use new strategies, like encouraging children to speak up about their experiences and feeling. One participant shared about her hopes for her children to be able safely express their feelings.

I think our kids, they should be able to speak on how they feel. Parents, me as a parent, I know what's helping my kids is I told them to be totally honest. "It's okay. This is to help you. For them to help you, they have to know." I just want my kids...I want them to be able to...communicate in a more positive way. 
That's what we're working on...I don't know. I don't want them to be dysfunctional or go through what I had to go through. (P3)

By addressing safety concerns from both homelessness and DV, transitional housing allowed many participants to focus on their goals and needs related to parenting.

\section{Addressing Mental Health Needs to Enhance Relationships}

Another perceived impact of DVTH on the parent-child relationship was the able to address mental health needs. During their stay in DVTH, participants described the role of mental health in their relationship with their children. One participant shared how their own mental health impacted their parenting.

I just worry about my kids 'cause I get off on my own emotional difficulties but I didn't know how to help my kids after I brought them in there. When I'm emotionally stuck, and mentally messed up, and I done already brought my kids in it, how do I get my kids out of it? $\mathrm{Me}$, I always find a way to let it go, move past it, but my kids they stay there, and it contributes to their decision making and how they feel about the world. (P27)

Many DVTH residents noted that the relationship between parent and child mental health was multidirectional, with changes in one, impacting the other. A participant reflected "The problem is, with the depression that I have, I don't want my daughter to feel more depressed." (P24) Most parents shared they had mental health concerns for themselves and their children. Mental health symptoms, in particular depression and anxiety, were motivations to seek external help for meeting parenting and relationship goals. Particularly for participants with teenagers, addressing parenting and child mental health needs was an approach to improving family connections and healing from trauma. A resident shared how she was attending counseling to be a bigger support to her daughter, noting "I'm trying [counseling], and I'm trying especially for her because I know how easy she could slip back into-it went from being suicidal to her cutting, and I know how easy she could slip back into that." (P13).

Feeling down, depressed, or experiencing trauma impacts could interrupt parenting and family goal-setting, but children also helped improve mental health symptoms, as one DVTH resident shared.

Right now, what I'm thinking about is my kids, how to get us back afloat. How to make them happy again, because when they see me upset or they see me crying, they'll sometimes feel-they'll see. When I know they're busy or I think they're asleep or something and I'm crying, they'll come and just hug me and say, "It's okay, Mom, you're doing what you can do, and we're all in this together." Then I feel okay cuz I think, "Wow." I've been through a lot in my life. (P13)

One DVTH resident further explained the positive impact of children "My own emotional state does not allow me to do things. Once the girls arrive, I feel better. If it weren't for my daughters - they are the propellers of my life." (P24) DVTH allowed residents valuable time to address mental health needs of the family, which was perceived to improve the parent and child relationship.

Co-parenting challenges. A major factor limiting the impact of DVTH on residents' parent and child relationships and mental health were conflicts and tense custodial arrangement with the (former) partner. The impact of the former partner on parent and child relationships and mental health was referenced by several participant a barrier to relationship growth, with one noting "I'd like for the children's father to let me go, to leave me alone." (P21) Former partners were thought to comprised the parent and child relationship improvements made in DVTH through coercive actions and safety concerns. Another participant shared:

What happens is that since my husband has visits with the children, they go back to him, and I feel like they come back very manipulated by him. So, it's not irritability. I think it's frustration in seeing the power he has as a dad to influence them in a bad way, to behave in a bad way because, even the way they are with each other, between my two children, it's evident that there is verbal aggression. (P7)

Throughout the stay at DVTH, many participants had to negotiate contentious and unsafe custody exchanges, parenting differences, and the resultant impacts on child behavior. Safety concerns in particularly hindered perceived mental health impacts for survivors and children.

Due in part to continued conflict and safety concerns from their former partners, a parenting goal for participants during their time in DVTH was to prevent the potential generational transmission of violence from childhood exposure. Transitional housing stays were seen as a way to achieve safety, resources and time for parental focus to meet this goal One DVTH resident noted "I just want my kids to be good. I don't want them to-I don't ever want my son to be an abusive man." (P23) Another participant shared how she approaches violence prevention with her children "I'm constantly talking to the boys to make sure that I'm not overlooking anything that could be hindering them to being the upmost best men in this society" (P4) An impact of DVTH for many participants was the ability to stabilize the family in the hopes of preventing future violence. One participant shared her approach for prevention with her children.

I don't want them to be stuck with their previous outlook on life because of this whole situation. There's 
always something. There's always a future, and the possibility to move forward, with effort, dedication, affection, and, more than anything else, with support from people. (P7)

Instilling hope for the future was a strategy residents engaged in to address the impact of violence and to build family relationships while in DVTH.

\section{Improving Family Stability after Violence and Trauma: Program Strengths and Barriers}

Family wellness was a primary goal for virtually all study participants, which was facilitated and hindered by programmatic features. Given time to focus on each other and mental health issues paved the way for greater family stabilization. Participants indicated that DVTH assisted with families being able to establish safety and a sense of getting back to normalcy, leading to enhanced family wellness. However, living in a community of families who have also experienced trauma sometimes negatively impacted the sense of safety and normalcy.

\section{Establishing Safety, Getting Back to "Normal”}

For participants in this sample, housing, first in the form of shelter and then DVTH, was a critical goal for stability and safety. Housing allowed DV survivors to focus on their children's primary needs, including (1) improving safety, (2) stabilizing trauma impacts (3) filling educational and material resource needs. Establishing safety was a major parenting goal, especially when first moving into DVTH to address family needs, as one participant shared:

My main goals are to have a job, to succeed, leave all this in the past, and provide safety for my daughters, make them feel that we are not going to live through that moment, make them feel safe. For my daughter to graduate and continue going to school. (P24)

For many participants, the safety features at onsite DVTH, including security, staff, and gates, improved parent and child feelings of safety, and thus overall wellness. One DVTH resident shared the early impact of DVTH on emotional safety and wellbeing for her children.

My kids are changing so much. I mean, this is the first time we've been free, but we're releasing all our emotions that we've had, years of emotions that have been held in. They're all coming out, but as they're coming out, we're healing from it. (P3)

Having the security of their own safer space led to a sense of freedom and ability to address the trauma they had experienced, increasing stability. Addressing child trauma and educational impacts from violence, homelessness, and other life events helped to improve family safety and wellness throughout the DVTH stay. Sharing about service needs for her children, one participant noted "People don't realize that kids, even though they didn't get hit or be-it doesn't mean that they didn't experience trauma. They experienced trauma right with you." (P3) Given time to establish safety, DVTH provided parents space to reflect on the trauma they and their children had experienced.

DVTH was a preferred parenting environment over emergency shelter for family safety and stability. While shelter provided initial physical safety, it was generally considered by study participants as an invasive and stressful environment for families, especially children. Stressors at shelter included cramped quarters, surveillance, a paucity of food options for preparing meals, and a lack of autonomy over routines for families. One resident explained how her experience with her children in shelter spurred her interest in DVTH.

The shelter took me in and the kids. We're all sleeping in one room. It was difficult sleeping four people in one room. I remember my kids were fine with it. They never complained once about being in that room, but I remember the first night we were there I just cried myself to sleep, cuz I was-I had kids with their beds on the floor. (P13)

Conversely, units at the DVTH site offered families a chance to increase stability gained from shelter by allowing physical and emotional space to have needs addressed. One resident shared the impact of her child of getting her own room.

That was one of the problems she had which caused her grades to drop, but eventually, since we have been living at the apartment where we are now, she has more space, she has more privacy in her own room, she is more motivated, but she is doing well, now. (P24)

Single family apartments with multiple bedrooms offered by DVTH allowed families to have a semblance for normalcy and help with school, easing parenting tensions and fostering healing.

The ability to meet family material needs in DVTH increased stability and safety, improving overall wellness for both parents and children. Having housing at DVTH, at least initially, reduced family stress, gave parents more autonomy and authority with their children, and increased safety for many participants. When residents first move into DVTH, their primary concerns were directly addressing child needs through youth-oriented services, education, or resources and indirectly addressing child needs by stabilizing family mental health and economics. A participant shared her delight when her kids' clothing needs were met right away after they 
moved into DVTH. "That was really cool, and the kids came back super excited. "Hey mom, we picked their own clothes out." (P4) She went on to explain,

I think without [DVTH program], trying to do everything on my own, it would have been-probably it would have just took me a lot more time. Instead, of being able to not have to worry about the rent and the bills, and then the necessities that the kids' needs. Really, working, even when you go to a relative's house, you can't get the support that was given here. (P4)

Participants shared the importance at move-in of getting their child enrolled in school, to the doctor, and having their space in the apartment set up as central to the family's needs. Access to medical care and enhance resources helped improve DVTH resident wellness.

\section{Living in a Traumatized Community}

While many participants indicated that DVTH increased stability and overall wellness, for some families the atmosphere was challenging. The environment at DVTH was reported by some participants, especially those later in their stay, as inconducive to raising healthy children, both because of other children's behavior problems and conflicts between adults. One DVTH resident explained her experience with other parents at DVTH.

All you see is just frowns and walking around mad at one another and, "Well, you bitch, you did this on Facebook. You took my man. Dah, dah, dah." Like I said, they're teaching their kids to go in the house and, "Momma, she said such-and-such about you." Then here comes momma outside. It's just ridiculous. (P15)

Conflict between the residents and their children created tension in the environment. Staff were sometimes brought in to intervene, though largely these conflicts were resolved among the residents themselves. The high level of conflict among some residents had a spillover impact of creating distrust with other residents, especially those who were perceived as interfering with parenting.

I just don't trust these people. This lady, she cursed at the kids, but they don't say nothin' about that. Other people, they raise their kids differently. My kids are raised with respect. You hit my kid, my kid has a right to knock your kid out. I'm not playin'. I feel like I was too nice to these women too many times. I'm done bein' nice and that's just where I'm at. I feel like these people don't care about you. Staff don't care. How can they care if they settin' you up for failure? (P20)
Participants used a variety of different strategies to navigate the sometimes-intense parenting environment at DVTH, including avoiding engagement with other residents, keeping children inside the apartment at all times, and leaving on the weekends to avoid periods of time when many staff members were not present. One DVTH participant shared:

That's why I just stay inside and keep my kids-try to keep the kids inside. I try not to be here on the weekends 'cause it's so ridiculous. It's like living with middle school girls all over again. It was like you would think we're grown women, and then a situation that we're in, you would think it'd be better. (P5)

Limiting contact with other families at DVTH was a way to manage the environment, as one participant stated. "I was letting my kids go outside and interacting with kids, but them kids are new to the program, too, and I don't want them to pick up any more behaviors than what they have." (P3).

An additional limitation of the impact of DVTH on family stability and wellness was the time-limited nature of the housing program. DV survivors near their time limits often saw their stress increase, especially related to their needs and goals as parents. One DVTH resident getting close to her move out date said "Right now I am feeling very distressed, I can't sleep. I know I will end up out on the street with my children because I need help to pay for rent." (P21) Another close to moving out added:

If I had a family, I wouldn't be as scared as I am, but since I don't have any extensions, other than me and [child's name], it is scary because it's my life. It's her life. If I don't have anything else to protect us or anything like that, it's a very scary, daunting feeling day in and day out. (P23)

Financial instability preventing permanent housing was a major source of parenting stress that limited stability. One resident stated, "I feel like I might have to give my fucking kid up for adoption 'cause I have no money." (P23) Another resident shared about the skills she would have liked to develop in DVTH.

I would actually want somebody to help me learn how to manage my money instead of spendin' it every time I got it. I would like to learn how to manage my own money for I could get a house for these kids, cuz that's my goal. (P16)

To address these limitations, some residents indicated a need for more economic supports and financial skills development opportunities at DVTH to help them overcome the barriers they face meeting their housing goals and having long-lasting stability for their children. 


\section{Accessing Resources}

DVTH offered an opportunity to access resources both for children and parents that addressed family needs. While participants were able to access resources available at DVTH to some extent, barriers to addressing needs limited program impact on family wellness.

\section{Receiving Help}

Prior to entering DVTH, many participants reported a lack of supportive networks, frequently caused by social isolation from the partner using violence. The programming offered at DVTH for parents, children, and families was impactful to some participants in furthering community connections and meeting goals. Frequent child and parenting support needs identified by participants at DVTH were counseling, educational accommodations, and childcare. DVTH residents typically work with an advocate, and in some cases, a counselor, to meet individual and family needs. The relationship between the resident and the advocate can help facilitate meeting needs and goals for the whole family, increasing wellness, stability and overall DVTH program impact. One participant shared about her advocate "I'm too grateful for this girl. Seriously, girl, I'm really passionate about when I'm talking about this because really, it really touched my heart...helped me to get the necessities with the diapers and formula, everything." (P4) Participants struggling with parenting and child behavior issues shared that the support of staff related to their child behavior reduced stress, enhanced efficacy as a parent, and helped them feel more comfortable in the DVTH environment. One participant shared,

They [DVTH staff] haven't got on to me about my kids at all. We've been able to-he's been able to act crazy, and they still treat him the same. They're like, we work through it and keeps on going. The children's staff are wonderful and the other staff. Most programs will get onto you about your kids. They understand, and they just let the kids go with the flow. They try to let 'em just be. You know? (P3)

Another participant echoed the importance of support services for children in helping her family heal.

My oldest daughter was doing counseling. Then, I just started with,parenting and family support.. I know they starting with me and then they do families so we're good... Childcare, very good because, after my kids went back to school, I've had the opportunity for my children to go to activities after classes; after school. And the people who have been supporting me with that have been very efficient. (P7)
For participants that were able to get parenting support, childcare, and counseling at the beginning of and throughout their DVTH stay, it was a stabilizing force that impacted overall family health. Another DVTH resident shared about how staff support helped her address child behavior during a challenging time helped her as parent.

Just being able to speak with [counselor], and share some of my son's- their input on things and views on things and [counselor] really was there for me even as a parent 'cause you'd be like oh, my God sometimes. You didn't know your child would do a thing like that. They would say something that sours you, oh, wee, good Lord, where did that come from, but [counselor] is like, "It's okay. Just let him express himself the way he wants to". (P25)

Participants in this study routinely accessed parenting and child services outside of the DVTH program, sometimes by choice and other times through mandate, due to involvement in the Child Protective Services (CPS) system. Voluntary engagement with services for children and parenting for participants in this study included external counseling, children's psychiatric care, healthcare, and youth mentoring programs. External youth program and school connections were generally thought to be supportive to help meet parenting goals and to increase the family support system. One DVTH resident shared about her rapport with a long-serving school counselor.

I was just talkin' to my daughter's counselor today. I was like, "I got one more comin' at you." She was just talkin' to the high school. She was like, "Okay, I'll be ready." She's been there. I have six. She's been there with all of 'em. (P15)

Other participants reported getting parenting support from childcare staff, community mental health staff, and medical care providers external to the DVTH program.

Several participants in the study had engagement with CPS. At the initial interview after move-in to DVTH, seven participants indicated involvement with CPS, which was then resolved with closed cases without removals for four of these participants. An additional three participants had CPS cases initiated during their DVTH stay, and one removal of a child was reported to the study team. Engagement with CPS was a source of stress, and not supportive, for virtually every participant involved with child welfare in this study. A DVTH residents discussed frustrations navigating CPS system requirements.

I have already applied for a restraining order and my CPS worker and the police said-I waited there for, like, four hours. They told me I couldn't get a restraining order because I had warrants. "So what if he kills 
me, and you all saying I can't get a restraining order?" THEY [CPS] wanted me to get a protection order, and I did, but I couldn't get it because I have warrants, but they just tickets. They're [DVTH program] gonna try to help me pay for it. (P16)

DVTH residents with CPS involvement routinely expressed a desire to have DVTH staff advocate for them with CPS regarding their case, and help them address barriers, such as longer-term housing, to end CPS involvement. When DVTH staff was able to advocate in external agencies and systems for residents, it increased trust and rapport with families. For CPS-involved DVTH residents, the housing program had the strong potential for positive impacts via case resolution and supportive advocacy services.

\section{Encountering Program Barriers}

Several parents in this study reported waits for counseling and childcare offered at the DVTH, which hindered family progress on goals, safety, and stability. Some participants were unable to work, medical appointments, or school because they didn't have childcare, which was a major source of stress. One participant described the long wait for the onsite daycare, "Like I said, [staff] from the shelter, she-my boys are next on the list. I don't know how long I'm gonna have to wait." (P14). When parents were not able to get counseling or childcare through the DVTH program, they often found support at other agencies to get their children help. One parent shared how a "Wraparound" service model helped her when the DVTH program was unable to address her needs.

I've been telling them I've needed counseling for my kids. The only reason my kids have such a good support behind them now is 'cause I went off at the school. ... Now we're with Wraparound, now we're getting everything. I did this on my own. Everything my kids need I've been telling them, but at the same time I'd rather just go out and do it because nothing gets done here. (P5)

Negative interactions with DVTH staff hindered trust in the agency and limited service access, especially as it related to child services. After having a negative experience with a counselor for herself, one participant shared "I also don't want counseling from program for her [daughter].” (P24) Feeling minimized or unseen by DVTH child-related staff impacted perception of service quality and a sense that the agency could provide caring help, as illustrated by the experience of one resident.

I asked for a mentor program for [son] to be into some type of mentor program and I know they have the accessibility to make that happen. I wasn't happy when the referral was given ... This guy came to my house and I was in a crisis. He went over and addressed my son and called him the wrong person. My son was like, "I don't ever want to talk to him. He can't even come over here and introduce himself".... I was like, "If we're gonna go about trying to get my son plugged in with the right type of people, can we please make sure your staff know who they're coming to address? Can you know my son's name?" Because it didn't make him feel good that he was being approached by a stranger and then you wanna have a man-to-man conversation, but you don't even know the person you are speaking to. (P8)

When vital children's services and supports were not available or when children were not prioritized in the program, families experienced frustration and stress, which limited trust in the program and thus, program impacts.

For a handful of residents, the visitor policy at the DVTH program limited their ability to have needed social supports to manage child needs and behaviors. A DVTH resident who had newly moved in shared the limitations the visitor created for their family.

We cannot have visitors. I think you can, but you have to ask for two weeks in advance, and it cannot be anybody. Not anybody can come here, because if they have been locked up or have a criminal background, they cannot come in here. (P24)

While strict visitor policies are in place for as safety measures for the overall community, they also can lead to further isolation for DV survivors and their families, limiting the potential connective benefits of the housing program,

Some of the most unmet service needs for parents and children were family activities. As one resident noted, "Those children there, it's just there's nothing for them to do." (P15). Across their stay and especially after the initial move in period, residents wanted more reliably available recreational activities for children, both those facilitated by staff and for parents and children together. Family activities were thought by residents to be helpful to addressing some of the chaos of the DVTH environment. "...Like kids and moms going to activities together and different stuff like that. Nothing that has to do with any money or anything, or doing things together like a spa day, treating each other." (P3) Joint activities were perceived to have the benefit of increased bonding and relaxation for families experiencing stress. The lack of family and childbased recreation could at times limit program impact. 


\section{Discussion}

Housing programs, with a focus on support and stability, are recognized as a community level approach to preventing and reducing interpersonal violence by increasing safety and reducing harm (Niolon et al., 2015), but have not been tested for potential benefit for children exposed to DV. Thematic analysis methods of 82 interviews with 27 parents with minor children were employed to uncover insights into the understudied area of children in projectbased DVTH. Three themes were developed from data analysis related to the potential impact of DVTH on parenting and child wellness: (1). DVTH gives space to strengthen the parent child relationship, improving connections after violence; (2). Transitional housing improves family stability by providing material, housing, and economic support, increasing parent, child, and family wellness; and (3). Programs available at and outside of DVTH are vital resources for family healing when accessible and survivor-centered. Study findings indicate that DVTH has the ability to positively impact both children and parents by enhancing family safety and stability after violence, but resource access and the program environment can limit potential benefits. These study findings underscore the primacy of children for DV survivors-for the virtually all participants, child needs were the priority when entering DVTH, and guided family goals.

Time at DVTH allows focus on the parent-child relationship, and strengthening of family support networks after the isolation from abuse and trauma. Participants shared that, in large part, DVTH helped them improve the parent-child relationship by providing a place to connect and addressing family mental health, which were major needs after violence experiences. These opportunities for connection may have the opportunity to strengthen attachment bonds, resulting in improved relationships. Given the dynamic and transactional nature of parent mental health with child mental health (Lorenzo et al., 2021), the opportunity in DVTH to get mental health care can also improve the parent-child bond. Study findings also revealed that gains in the parent-child relationship were compromised by co-parenting with an abusive partner, which decreased family safety. Parents who are survivors of DV face added safety risks for themselves and their children when they leave an abusive relationship, requiring navigation and contact with the former partner through visitation and exchanges of children, decisions around schools and children's medical needs (Bancroft et al, 2012; Parker et al, 2008). This study joins others (Epstein \& Goodman, 2019; Meier \& Dickson, 2017) in indicating the need for more civil legal remedies for DV survivors navigating civil court processes related to child and parenting needs. Housing programs working with DV survivors and their children should continue to offer adult and youth mental health and civil legal advocacy, and extend these programs in depth and attention to family needs.

Studies of mothing in the context of DV has often taken a deficit model approach, with the focus often being 'failure to protect' (LaPierre, 2008). Mothers in DV shelters have reported high levels of parenting surveillance, which in some cases led to diminished opportunities to parent as needed and a reduced likelihood of asking for support (Fauci \& Goodman, 2020). A study by Greeson et al. (2014) found that children living with DV showed more behavioral problems, but that these issues were related to living in a stressful context, not the result of maternal parenting practices. The current study adds to a growing body of literature that highlights how mothers who are DV survivors strongly value and prioritize their relationships with their children, and they should receive strengths-based services that acknowledges the challenges of parenting within the context of DV. Hamby et al. (2018) note that a poly-strengths approach is critical to working with DV survivors, adding that multiple strengths and resources can enhance positive elements in family life. Housing programs like DVTH benefit families by enhancing resources and building on existing strengths to counter act trauma impact and build needed supports.

Families are better able increase wellness and stability not only when they not only have their own safer housing unit, but have the material and support needs reduce parental and child stress. The limited length of stay in DVTH creates added pressure on parents, and on their parenting, increasing stress and threatening program impacts. Residents face the challenges of finding permanent, affordable, and safe housing while maintaining stability for their children, which may increase parental stress, compromising relationship gains. Recent research on economic remedies for DV survivors, including the use of flexible funds to secure housing, highlight the reciprocal benefit of reduction of stress on parents and children when DV survivors secure housing for their family (Bomsta \& Sullivan, 2018). This study underscores the potential benefit of DVTH in reducing parental stress, with a note of caution about stress increases close to move out dates, especially in communities where safety permanent housing is difficult to obtain. Whenever possible, programs should omit or make very flexible length of stay requirements, and provide intensive supports early to help DV survivors find safe and affordable permanent housing as a way to reduce family stress and increase safety.

For virtually all participants, the safety offered by DVTH came from stability of being housed. While some participants benefited from the attention to security in the built environment of DVTH, high levels of conflict among residents onsite impaired feelings of safety among residents, especially related to their children. Environmental and 
programmatic concerns were frequent barriers to DVTH meeting its potential for families. The site-specific DVTH setting, with many families mutually experiencing trauma recovery, safety concerns, mental health needs, and economic instability, was considered a tough environment for many to raise children. Living in proximity with many others who have experienced trauma can lead to powerful connections as DV survivors; but can also lead to challenges, tension, conflict and can lead to further isolation (Hetling et al, 2020). Programs need to address environmental safety concerns and resident conflicts through peer support and restorative practices, and through attention to design, community safety, and environment to reduce conflict and increase opportunities for social support. This may mean for DV survivors without significant safety concerns, moving some transitional housing units to the community would increase parent and child safety.

\section{Implications}

The importance of non-judgmental support from DVTH staff, for parenting skills, resource acquisition, and quick access to services, especially childcare, were protective measures for children and their parents in this study. Recent work has indicated the critical underpinning of DV services for parents and children include education on the impact of DV exposure; trauma informed care service frameworks; cultural humility; and collaboration with families and other agencies to meet family needs (Berg et al., 2020). This study joins two recent statewide assessments (Wood et al., 2021; Berg et al., 2020) indicating the urgent need for more resources and support for parents and children in DV housing, including transitional models. Social workers in micro and macro roles need to increase attention to the needs of children exposed to DV, and the parenting needs of survivors in practice. Residents of DVTH and other DV programs need supports such as CPS systems advocacy, child activities, family therapy, childcare, prevention programming, and parenting support. Childcare is critical to DVTH parent resident success, and should be offered at move-in to all residents who need it for work, school or respite. Social worker should increase advocacy for access to affordable and trauma-informed childcare. While most parenting supported offered through DV programs is in the context of CPS-mandated services, this study indicates a need to offer supportive family-based programming to all DVTH residents with children that is inclusive, strengths-based, and non-judgmental, aligning with core social work values and trauma-informed practice principals. Given participants expressed goals to prevent their children from being victims or perpetrators of DV, youth prevention programs would meet family goals of intergenerational violence prevention. The study indicates that DVTH programs may have positive impacts on CPS case resolution and child safety, which merits further exploration. Multi-site, longitudinal, mixed-methods research is needed to bolster our understanding of the efficacy of DVTH on children and parents.

\section{Limitations}

Exploratory methods are helpful to understanding potential or perceived impact, but they cannot assess program benefit fully. This study is limited by the use of a single DVTH site. Program models, context, and service availability will vary at different programs. Community factors, such as the availability of affordable housing, shape participant experiences and thus are represented in their perception of program impacts. No youth residents were interviewed for this study, limiting our ability to understand their perspectives and experiences. These data were also collected before COVID-19 and perception of program benefit may shift after the experience of a global pandemic, and resultant personal and community challenges.

\section{Conclusion}

Study results indicated specific DVTH program aspects may benefit parent-child relationships and bond, increase family stability, and bolster resources and strengths after trauma and violence, making demonstrative impacts of residents and their children. Study findings also bring to light the complexity of communal living, separation violence, and mental health needs for DV survivors who are parenting. While DVTH programs have the opportunity to offer stability to families, attention to community safety, service availability, staffing quality, and parental stress are needed to improve child-parent relationships and help families meet goals. Housing, when coupled with DV support services, offers a powerful potential tool to address family needs, especially in the wake of the economic and mental health toll of the COVID-19 pandemic. Further study is needed to examine the direct and indirect impacts of DVTH on parenting, and family wellness, with an emphasis on longitudinal methods that incorporate youth voice. Addressing the needs of children exposed to DV and their parents-a population at high risk for subsequent violence- should be a public health and social work priority. Housing provides a potentially powerful remedy for future violence prevention by enhancing safety, increasing stability and building parent-child relationships.

Funding Data for this research was taken from project 3424201 from the Office of the Governor, Criminal Justice Division, State of Texas. Findings do not reflect the views of CJD. 


\section{References}

RE Anderson LJ Edwards KE Silver DM Johnson 2018 Intergenerational transmission of child abuse: Predictors of child abuse potential among racially diverse women residing in domestic violence shelters Child Abuse \& Neglect 858090 https://doi.org/10.1016/j. chiabu.2018.08.004

BOH Annor A Oudshoorn 2019 The health challenges of families experiencing homelessness Housing, Care and Support 22293105 https://doi.org/10.1108/HCS-12-2018-0036

R Bai C Collins R Fischer D Crampton 2019 Pursuing collaboration to improveservices for child welfare-involved housing unstable families Children and YouthServices Review $104110 \mathrm{https} / / /$ doi. org/10.1016/j.childyouth.2019.104405

MH Bair-Merritt M Blackstone C Feudtner 2006 Physical health outcomes of childhood exposure to intimate partner violence: A systematic review Pediatrics 1172 e278 e290 https://doi.org/10. 1542/peds.2005-1473

CK Baker KA Billhardt J Warren C Rollins NE Glass 2010 Domestic violence, housing instability, and homelessness: A review of housing policies and program practices for meeting the needs of survivors Aggression and Violent Behavior 15430439 https:// doi.org/10.1016/j.avb.2010.07.005

CK Baker P Holdtich H Oliphant 2009 A descriptive analysis of transitional housing programs for survivors of intimate partner violence in the United States Violence Against Women. 154460481

L Bancroft JG Silverman D Ritchie 2012 The batterer as parent: Addressing the impact of domestic violence on family dynamics Sage

Bassuk, E. L., DeCandia, C. J., Beach, C. A., \& Berman F. (2014). America's youngest outcasts: A report card on child homelessness. The National Center on Family Homelessness, American Institutes for Research.

EL Bassuk JA Hart E Donovan 2020 Resetting policies to end family homelessness Annual Review of Public Health 41247263 https:// doi.org/10.1146/annurev-publhealth-040119-094256

KA Berg AE Bender KE Evans MR Holmes AP Davis AI Scaggs JA King 2020 Service needs of children exposed to domestic violence. Qualitative findings from a statewide survey of domestic violence agencies Children and Youth Service Review 118110

MC Black KC Basile MJ Breiding SG Smith ML Walter MT Merrick MR Stevens 2011 The National Intimate Partner and Sexual Violence Survey (NISVS): 2010 Summary Report. Atlanta, GA: National Center for Injury Prevention and Control, Centers for Disease Control and Prevention.

H Bomsta CM Sullivan 2018 IPV survivors' perceptions of how a flexible funding housing intervention impacted their children Journal of Family Violence 33371380

J Bowlby 1973 Attachment and loss: Volume II: Separation, anxiety and anger The International Psycho-Analytical Library 951429

V Braun V Clarke 2006 Using thematic analysis in psychology Qualitative Research in Psychology 3277101 https://doi.org/10.1191/ 1478088706qp063oa

V Braun V Clarke 2021 Thematic analysis: A practical guide Sage

MJ Breiding KC Basile J Klevens SG Smith 2017 Economic insecurity and intimate partner and sexual violence victimization American Journal of Preventive Medicine 534457464 https://doi.org/10. 1016/j.amepre.2017.03.021

J Campbell AS Jones J Dienemann 2002 Intimate partner violence and physical health consequences Archives of Internal Medicine $1621011571163 \mathrm{https} / / /$ doi.org/10.1001/archinte.162.10.1157

GL Carpenter AM Stacks 2009 Developmental effects of exposure to intimate partner violence in early childhood: A review of the literature Children and Youth Services Review 318831839 https://doi.org/10.1016/j.childyouth.2009.03.005
CFR $\S 91.5$ (2020).

CE Chandler AE Austin ME Shanahan 2020 Association of housing stress with child maltreatment: A systematic review Trauma, Violence, \& Abuse. https://doi.org/10.1177/1524838020939136

A Chanmugam K Hall 2012 Safety planning with children and adolescents in domestic violence shelters Violence and Victims 276831848

AE Chiesa L Kallechey N Harlaar C Rashaan Ford EF Garrido WR Betts S Maguire 2018 Intimate partner violence victimization and parenting: A systematic review Child Abuse \& Neglect 80 285300 https://doi.org/10.1016/j.chiabu.2018.03.028

Clark D Wood L Sullivan C 2019 Examining the needs and experiences of domestic violence survivors in transitional housing. Journal of Family Violence 344275286

A Clough JE Draughon V Njie-Carr C Rollins N Glass 2014 Having housing made everything else possible: affordable, safe, and stable housing for women survivors of violence Qualitative Social Work 135671688

M Cyr DS Pasalich RJ McMahon SJ Spieker 2014 The longitudinal link between parenting and child aggression: The moderating effect of attachment security Child Psychiatry \& Human Development. 45555564 https://doi.org/10.1007/s10578-013-0424-4

MB Enlow B Egeland EA Blood RO Wright RJ Wright 2012 Interpersonal trauma exposure and cognitive development in children to age 8 years: A longitudinal study Journal of Epidemiology \& Community Health. 6610051010

D Epstein L Goodman 2019 Discounting women: Doubting domestic violence survivors' credibility and dismissing their experiences Pennsylvania Law Review 167399461

N Etherington L Baker 2018 From "Buzzword" to best practice: Applying intersectionality to children exposed to intimate partner violence Trauma, Violence, \& Abuse 1915875 https://doi. org/10.1177/1524838016631128

JE Fauci LA Goodman 2020 "You don't nobody else knocking you down": Survivor-mothers' experiences of surveillance in domestic violence shelters Journal of Family Violence 35241 255

RP Fearon MJ Bakermans-Kranenburg Van IJzendoorn, M.H., Lapsley, A., \& Roisman, G.I. 2010 The significance of insecure attachment and disorganization in the development of children's externalizing behavior: A meta-analytic study Child Development 812435456 https://doi.org/10.1111/j.1467-8624.2009.01405.x

VJ Felitti RF Anda D Nordenberg DF Williamson AM Spitz V Edwards MP Koss JS Marks 1998 Relationship of childhood abuse and household dysfunction to many of the leading causes of death in adults. The Adverse Childhood Experiences (ACE) Study American Journal of Preventative Medicine 14424558

PJ Fowler DS Brown M Schoeny S Chung 2018 Homelessness in the child welfare system: A randomized controlled trial to assess the impact of housing subsidies on foster care placements and costs Child Abuse \& Neglect 835261 https://doi.org/10.1016/j.chiabu. 2018.07.014

PJ Fowler AJ Farrell KE Marcal S Chung PS Hovmand 2017 Housing and child welfare: Emerging evidence and implications for scaling up services American Journal of Community Psychology. 60 134144

Fusco R A 2017 Socioemotional problems in children exposed to intimate partner violence: Mediating effects of attachment and family supports. Journal of Interpersonal Violence 321625152532. https://doi.org/10.1177/0886260515593545

M Greeson AC Kennedy DI Bybee M Beeble A Adams C Sullivan 2014 Beyond deficits: Intimate partner violence, maternal parenting, and child behavior over time American Journal of Community Psychology 544658

K Gurtovenko LF Katz 2020 Post-traumatic stress, mother's emotion regulation, and parenting in survivors of intimate partner violence 
Journal of Interpersonal Violence 35 3-4 876898 https://doi.org/ $10.1177 / 0886260517690874$

Hamby, S. L, Finkelhor, D., Turner, H. A., \& Ormrod, R. K. (2011). Children's exposure to intimate partner violence and other forms of family violence: Nationally representative rates among US youth. OJJDP Juvenile Justice Bulletin - NCJ 232272. Washington, D.C

S Hamby D Finkelhor H Turner R Ormrod 2010 The overlap of witnessing partner violence with child maltreatment and other victimizations in a nationally representative survey of youth Child Abuse \& Neglect 3410734741 https://doi.org/10.1016/j.chiabu. 2010.03.001

S Hamby J Grych V Banyard 2018 Resilience portfolios and polystrengths: Identifying protective factors associated for thriving after adversity Psychology of Violence 82172183

TI Herrenkohl C Sousa EA Tajima RC Herrenkohl CA Moylan 2008 Intersection of child abuse and children's exposure to domestic violence Trauma, Violence \& Abuse 928499 https://doi.org/10. $1177 / 1524838008314797$

A Hetling A Dunford H Botein 2020 Community in the permanent supportive housing model: Applications to survivors of intimate partner violence Housing, Theory and Society 374400416 https:// doi.org/10.1080/14036096.2019.1624388

J Houston J Grych 2016 Maternal attachment buffers the association between exposure to violence and youth attitudes about aggression Journal of Clinical Child \& Adolescent Psychology 455605613 https://doi.org/10.1080/15374416.2014.987380

C Humphreys K Diemer A Bornemisza A Spiteri-Staines R Kaspiew B Horsfall 2019 More present than absent: Men who use domestic violence and their fathering Child \& Family Social Work 242321 329 https://doi.org/10.1111/cfs.12617

J Humphreys K Lee 2005 Sleep disturbance in battered women living in transitional housing Issues in Mental Health Nursing 267771 780 https://doi.org/10.1080/01612840591008401

Jasinski, J. L., Wesely, J. K., Mustaine, E., \& Wright, J. D. (2002). The experience of violence in the lives of homeless women: A research project. Washington, DC, U.S: Department of Justice (NCJRS 211976).

Y Jinyao Z Xiongzhao RP Auerbach CK Gardiner C Lin W Yuping Y Shuqiao 2012 Insecure attachment as a predictor of depressive and anxious symptomology Depression \& Anxiety 299789796 https://doi.org/10.1002/da.21953

ME Karlsson JR Temple R Weston VD Le 2016 Witnessing interparental violence and acceptance of dating violence as predictors for teen dating violence victimization Violence Against Women 225625646

LB Klein BR Chesworth JR Howland-Myers CF Rizo RJ Macy 2019 Housing interventions for intimate partner violence survivors: A systematic review Trauma, Violence, and Abuse https://doi.org/ $10.1177 / 1524838019836284$

S LaPierre 2008 Mothering in the context of domestic violence: The pervasiveness of a deficit model of mothering Child \& Family Social Work 134454463

AA Levendosky GA Bogat AC Huth-Bocks 2011 The influence of domestic violence on the development of the attachment relationship between mother and young child Psychoanalytic Psychology 284512527 https://doi.org/10.1037/a0024561

NE Lorenzo S Zeytinoglu S Morales 2021 Transactional associations between parent and late adolescent internalizing symptoms during the COVID-19 pandemic: The moderating role of avoidant coping Journal of Youth and Adolescence. 503459469

K Malterud V Siersma A Guassora 2016 Sample size in qualitatve interview studies: Guided by information power Qualitative Health Research 261317531760

Mbilinyi, L. (2015). The Washington State Domestic Violence Housing First Program: Cohort 2agencies final evaluation report
September 2011-September 2014. Washington StateCoalition Domestic Violence. Retrieved from: https://wscadv.org/wpcontent/uploads/2015/05/DVHF_FinalEvaluation.pdf.

LA McWilliams SJ Bailey 2010 Associations between adult attachment ratings and health conditions: Evidence from the National Comorbidity Survey Replication Health Psychology 294446 453 https://doi.org/10.1037/a0020061

JS Meier S Dickson 2017 Mapping gender: Shedding empirical light on family courts' treatment of cases involving abuse and alienation Minnesota Journal of Law \& Inequality 352311334

J Mekolichick J Davis J Chouinard 2008 Transitional supportive housing in a rural location: A preliminary case study and lessons learned Journal of Applied Social Science 213646 https://doi.org/10.1177/193672440800200103

Mountain, A. M. (2015). The lived experience of battered women in transitional housing.Capella University, ProQuest Dissertations Publishing Number 3731881.

National Network to End Domestic Violence (2021). 15th Annual Domestic Violence Counts Report. Washington, DC. Retrieved from: NNEDV.org/DVCounts

PH Niolon AM Vivolo-Kantor NE Latzman LA Valle H Kuoh T Burton BG Taylor AT Tharp 2015 Prevalence of teen dating violence and co-occurring risk factors among middle school youth in high-risk urban communities Journal of Adolescent Health https://doi.org/10.1016/j.jadohealth.2014.07.019

N Nnawulezi S Godsay CM Sullivan S Marcus M Hacskaylo 2018 The influence of low-barrier and voluntary service policies on survivor empowerment in a domestic violence housing organization American Journal of Orthopsychiatry 886670680

Office on Violence Against Women (2020). Fiscal Year Fiscal Year 2020 Transitional Housing Assistance Grants for Victims of Domestic Violence, Dating Violence, Sexual Assault and Stalking Solicitation. https://www.justice.gov/ovw/page/file/12237 91/download.

J Olivet C Wilkey M Richard M Dones J Tripp M Beit-Arie S Yampolskaya R Cannon 2021 Racial inequity and homelessness: Findings from the SPARC Study The Annals of the American Academy of Political and Social Science $693182100 \mathrm{https}$ :// doi.org/10.1177/0002716221991040

T Parker K Rogers M Collins JL Edleson 2008 Danger zone: Battered mothers and their families in supervised visitation Violence against Women 141113131325 https://doi.org/10.1177/10778 01208324531

JL Postmus C-C Huang A Mathisen-Stylianou 2012 The impact of physical and economic abuse on maternal mental health and parenting Children and Youth Services Review 34919221928 https://doi.org/10.1016/j.childyouth.2012.06.005

CF Rizo LB Klein B Chesworth RJ Macy R Dooley 2020 Intimate partner violence survivors' housing needs and preferences: A brief report Journal of Interpersonal Violence 37958972

AR Rochelle 2017 Our lives matter the racialized violence of poverty among homeless mothers of color Sociological Forum: Special Issue: Whose Lives Matter? Violence, Social Control, And The Racial Divide 329981017

M Shinn SR Brown D Gubits 2017 Can housing and service interventions reduce family separations for families who experience homelessness? American Journal of Community Psychology. $607990 \mathrm{https}: / /$ doi.org/10.1002/ajcp.12111

C Sullivan 2018 Understanding how domestic violence support services promote survivor well-being: A conceptual model Journal of Family Violence 332123131

CM Sullivan D Cain 2004 Ethical and safety considerations when obtaining information from or about battered women for research purposes Journal of Interpersonal Violence 195603 618 https://doi.org/10.1177/0886260504263249 
CM Sullivan LA Goodman T Virden J Strom R Ramirez 2017 Evaluation of the effects of receiving trauma-informed practices on domestic violence shelter residents American Journal of Orthopsychiatry 88563570

JR Temple RC Shorey S Tortolero DA Wolfe GL Stuart 2013 Importance of gender and attitudes about violence in the relationship between exposure to interparental violence and the perpetration of teen dating violence Child Abuse \& Neglect 37343435

Z Turhan 2019 Safe father-child contact postseparation in situations of intimate partner violence and positive fathering skills: a literature review Trauma, Violence, \& Abuse. https://doi.org/10.1177/15248 38019888554

IE Udo P Sharps Y Bronner MB Hossain 2016 Maternal intimate partner violence relationships with language and neurological development of infants and toddlers Maternal Child Health Journal 20 14241431

Wood L Backes B McGiffert M Wang A Thompson J Wasim A 2019 Texas state plan 2018: Availability of services at Texas family violence programs and assessment of unmet needs of survivors of family violence. Submitted to Texas Council on Family Violence in revised September 2019

Wood L McGiffert M Wasim A Hairston D Backes B Baumler E Faulkner M 2021 Children exposed to domestic violence: Understanding the community service response and needs in Texasproject technical report. Center for Violence Prevention; The University of Texas Medical Branch.

C Zeanah Eds 2018 Handbook of Infant Mental Health 4 Guilford Press NY

Publisher's Note Springer Nature remains neutral with regard to jurisdictional claims in published maps and institutional affiliations. 